\title{
Tempat Sampah Pengelola Password Wifi dengan Algoritma TOTP SHA-3
}

\section{THETA DINNARWATY PUTRI, WINARNO SUGENG, GUNAWAN YUGA UTAMA}

\author{
Program Studi Informatika Institut Teknologi Nasional Bandung \\ Email : theta@itenas.ac.id
}

Received 12 Maret 2020| Revised 30 April 2020 | Accepted 25 Mei 2020

\begin{abstract}
ABSTRAK
Algoritma Time-Based One Time Password (TOTP) merupakan algoritma yang berfungsi menghasilkan password untuk satu kali pemakaian. Password yang dihasilkan memiliki batas waktu tertentu dan akan selalu berubah secara dinamis dalam periode tertentu. Algoritma TOTP menggabungkan secret key dengan current time yang kemudian dilakukan hashing menggunakan algoritma enkripsi SHA-3. Pada penelitian ini TOTP diaplikasikan untuk pengelolaan password wifi pada media tempat sampah dimana keterkaitan user dan kebutuhan mengakses wifi. TOTP akan menghasilkan password wifi untuk user jika user melakukan kegiatan membuang sampah pada media tempat sampah. Pada secret key dilakukan enkripsi menggunakan algoritma caesar terlebih dahulu sebelum dilakukan tahap hashing, ini agar membuat secret key dinamis sehingga variasi password menjadi lebih banyak dan dapat meningkatkan keamanan dari password. Dari hasil pengujian keluaran password tidak muncul secara berulang namun memiliki tingkat kemiripan sebesar 0,02\%.
\end{abstract}

Kata kunci: Internet Of Thing, TOTP, SHA-3, Tempat sampah

\begin{abstract}
The Time-Based One Time Password (TOTP) algorithm is an algorithm that produces a password for only one use. A password that is produced has a limited time and always changed dynamically in a specific period. The TOTP algorithm combines a secret key with a current time which is then hased with an encryption algorithm SHA-3. In this experiment the TOTP is applied for managing a wifi password for a user, when the user is throwing a trash at a particular bin. The secret key will be encrypted used a caesar algorithm before the hashing process, so that a secret key become dynamic and the password multiplied, and the security level will be higher. In this experiment the password output has not produced periodically but has a $0.02 \%$ similliarity.
\end{abstract}

Keywords: Internet Of Thing, TOTP, SHA-3, Trashbin 
Putri, dkk

\section{PENDAHULUAN}

Teknik keamanan dengan mengubah password secara dinamis dinamakan One Time Password (OTP) (Chandra, Wijaya, \& Budiman, 2019). OTP sendiri merupakan otentikasi dimana password dapat digunakan sekali pakai (Janakiraman, Sree, Manasa, \& Rajagopalan, 2018). Pada umumnya OTP digunakan untuk kebutuhan proses autentikasi yang dilakukan antara pihak server dan user.

HMAC based One Time Password (HOTP) merupakan algoritma pembangkit OTP berbasis algoritma HMAC. OTP dapat dihasilkan dengan input pada $n$-digit integer yang dapat diatur (Ramadhany, 2016). HOTP menghitung nilai input dari counter yang nantinya akan divalidasi dari pihak server kepada pihak client, password yang diakses pada masing-masing client tidak terikat satu sama lain sehingga masing-masing clientmemiliki nilai kunci unik yang tersinkronisasi pada server (Fakhrusy, 2016). Algoritma HOTPdikembangkan menjadi TimeBased One Time Password (TOTP).

TOTP merupakan algoritma yang berbasis algoritma HMAC dikembangkan dengan menggabungkan secret key dengan current timestamp sehingga dapat men-generate password sekali pakai dengan batas waktu (Ungkawa, Dewi, \& Putra, 2013). Pembentukannya menggunakan fungsi kriptografi secure hash algorithm.

Secure Hash Algorithm (SHA) merupakan teknik kriptografi yang pada tahun 1993 dikembangkan oleh National Institute of Standards and Technology (NIST) dan dipublikasikan sebagai Federal Information Processing Standards (FIPS 180) (Singh \& Raj, 2019). SHA menghitung nilai hash pada suatu pesan dengan panjang maksimal 160 bits untuk pesan dan hasil keluaran yang dinamakan message digest atau hash code. Namun ditemukan kelemahan pada algoritma $S H A-0$ sehingga pengembangan algoritma baru dari $S H A-1$ yang merupakan revisi dari $S H A-0$.

Keamanan dari SHA-0 dan $S H A-1$ berhasil ditembus dengan brute attack sehingga pada tahun 2012 algoritma keccak atau yang dikenal sekarang sebagai $S H A-3$ menjadi pemenang pada kompetisi untuk membuat sebuah standar baru yang diadakan oleh NIST. SHA-3 memiliki input dengan panjang yang tak terhingga, lalu pada ukuran output yang dimiliki SHA-3 berukuran beragam, mulai dari 224, 256, 384 dan 512 bits (Kurniawan, Kusyanti, \& Nurwasito, 2017), sehingga membuat $S H A-3$ menjadi lebih tahan terhadap serangan brute attack.

Pada masa sekarang jaringan wifi dapat ditemukan pada tempat umum seperti di kafe, taman, kampus maupun kantor (Andriani, 2020). Pada jaringan wifiyang bersifat umum dibutuhkan tingkat keamanan yang tinggi pada password wifi dikarenakan pada tempat umum memiliki tingkat kebahayaan yang tinggi, hal ini disebabkan perangkat yang terkoneksi pada jaringan wifi melalui gelombang radio sehingga siapapun dapat terkoneksi pada jaringan tersebut. Dengan hal tersebut maka keamanan data yang terkoneksi pada jaringan tersebut menjadi hal yang rentan (Kolhatkar, Joshi, Choudhari, \& Bhuva, 2018).

Besar kemungkinan adanya pencurian data yang dilakukan oleh orang yang tidak bertanggung jawab terhadap perangkat lain yang terkoneksi dalam jaringan tersebut (Huseynov \& Seigneur, 2016). Dengan hal tersebut maka penelitian ini membangun teknik keamanan yang dapat meningkatkan kerahasiaan kata sandi pada password wifi yang statis menjadi password wifi yang dapat mengubah secara dinamis untuk meminimalisir pencurian data dengan menggunakan algoritma TOTP SHA-3. 


\section{METODE PENELITIAN}

Metode proses pembuatan sistem dalam penelitian ini menggunakan model prototype. Dasar dari metode penelitian adalah dengan melakukan implementasi algoritma TOTP berbasis SHA3 yang dapat meningkatkan kerahasiaan kata sandi pada password sekali pakai untuk perorangan. TOTP memiliki secret key yang bersifat dinamis, hal tersebut dikarenakan secret key yang digunakan akan dienkripsi dengan teknik algoritma caesar terlebih dahulu yang perhitungannya dipengaruhi waktu. Current time dilakukan berdasarkan tanggal sehingga perubahan waktu melibatkan hari. Media tempat sampah akan memunculkan wifi beserta password agar user dapat mengakses wifi. Password yang sudah dipakai tidak akan bisa diakses lagi sehingga dibutuhkan password baru yang valid dengan cara membuang sampah pada media tempat sampah tersebut.

Penelitian ini bertujuan untuk melakukan implementasi algoritma TOTP dengan cara penggabungan secret key dengan current time. Kemudian dilakukan hashing menggunakan algoritma enkripsi SHA-3 dalam upaya meningkatkan pengulangan kemunculan passwordyang sama dengan melakukan pengujian pada model sistem pengelolaan password wifi pada media tempat sampah.

Perancangan sistem akan ditujukan dengan skema mindmapping yang berisikan bagaimana cara kerja antara user dengan sistem saling berkaitan, skema apa yang akan dilakukan user terhadap sistem, respon apa yang dilakukan oleh sistem dan bagaimana perancangan TOTP $S H A-3$ diimplementasikan ke media tempat sampah yang ditujukan pada Gambar 1 .

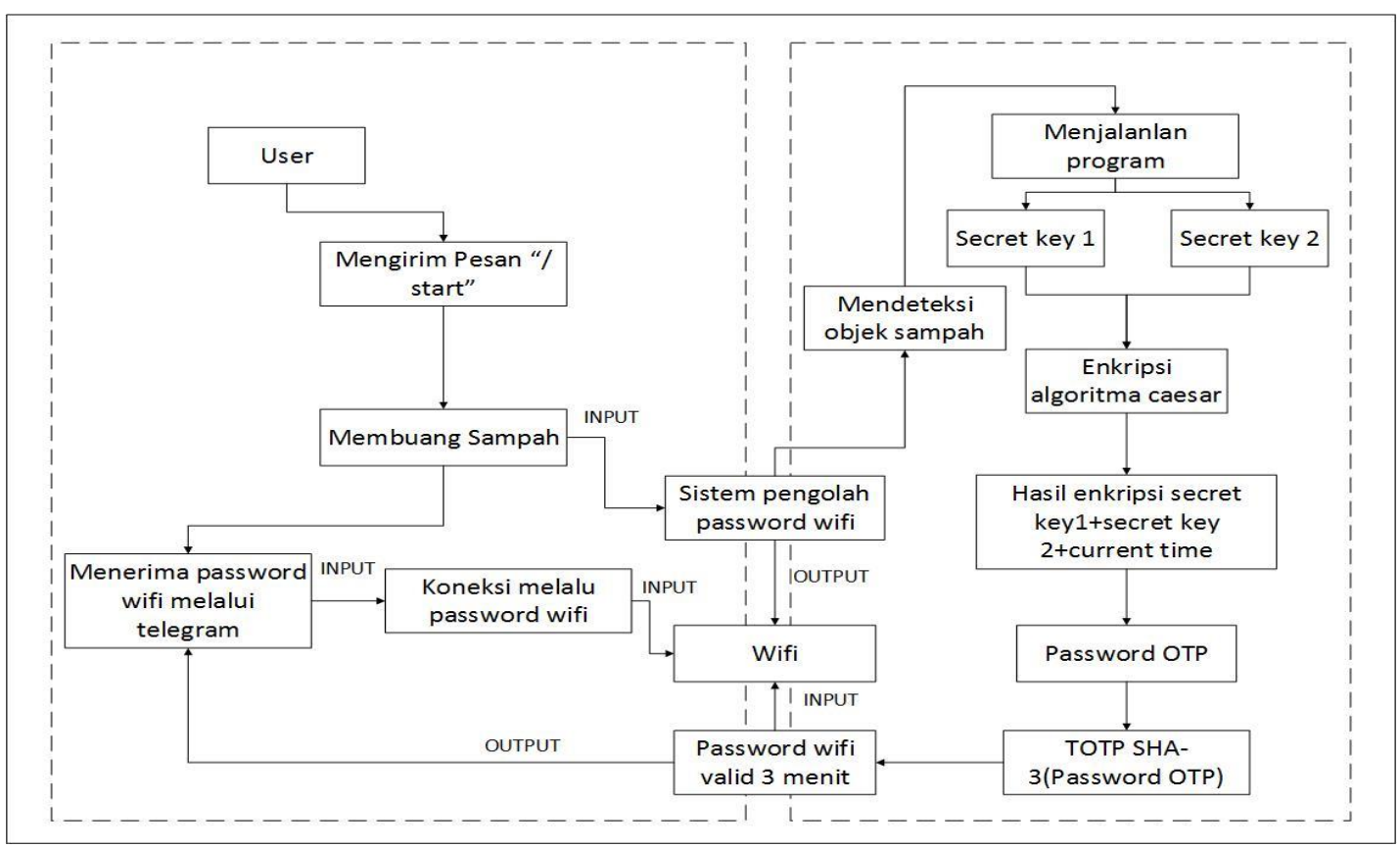

Gambar 1. Mind Mapping Proses Kerja Sistem yang Dibangun 


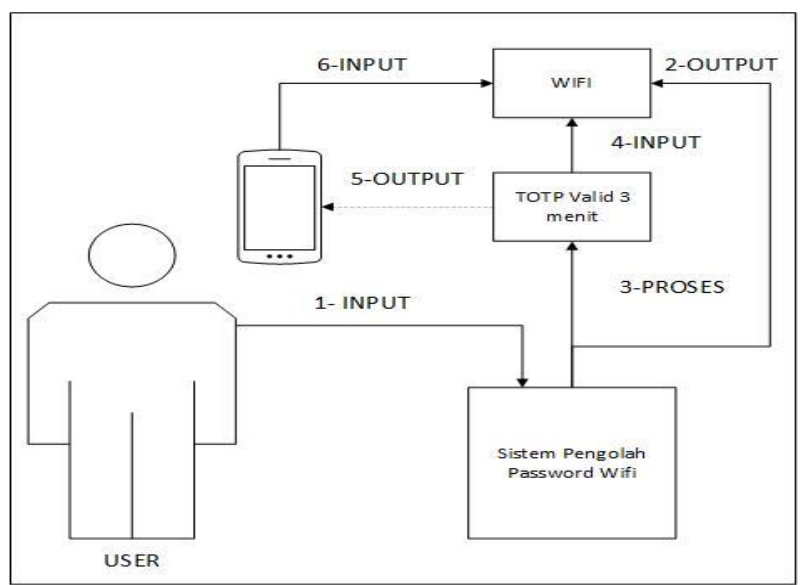

\section{Gambar 2. Skema Umum Perancangan Sistem Pengolah Password Wifi}

Berikut adalah penjelasan tahapan skema perancangan yang ditujukan pada Gambar 2 :

1. User melakukan aktivitas berupa membuang sampah pada media tempat sampah dianggap sebagai nilai input.

2. Media tempat sampah menyediakan wifi sebagai output.

3. Media tempat sampah akan men-generate atau melakukan proses TOTP yang dapat diakses selama 3 menit.

4. Hasil generate TOTP di input ke settingan wifi sebagai password wifi.

5. Hasil output generate TOTP dikirim ke user.

6. User dapat mengakses wifi dengan melakukan input password wifi dari TOTP yang telah diterima.

Penerapan TOTP selain menggunakan teknik hash SHA-3 juga menggunakan teknik enkripsi algoritma caesar, tujuan penerapan algoritma caesar yaitu untuk meningkatkan varian password dan meningkatkan keamanan. Algoritma caesar akan digunakan untuk mengenkripsi secret key pada kasus ini secret keyakan dibagi menjadi dua secret key skema implementasi algoritma caesar yang ditujukan pada Gambar 3.

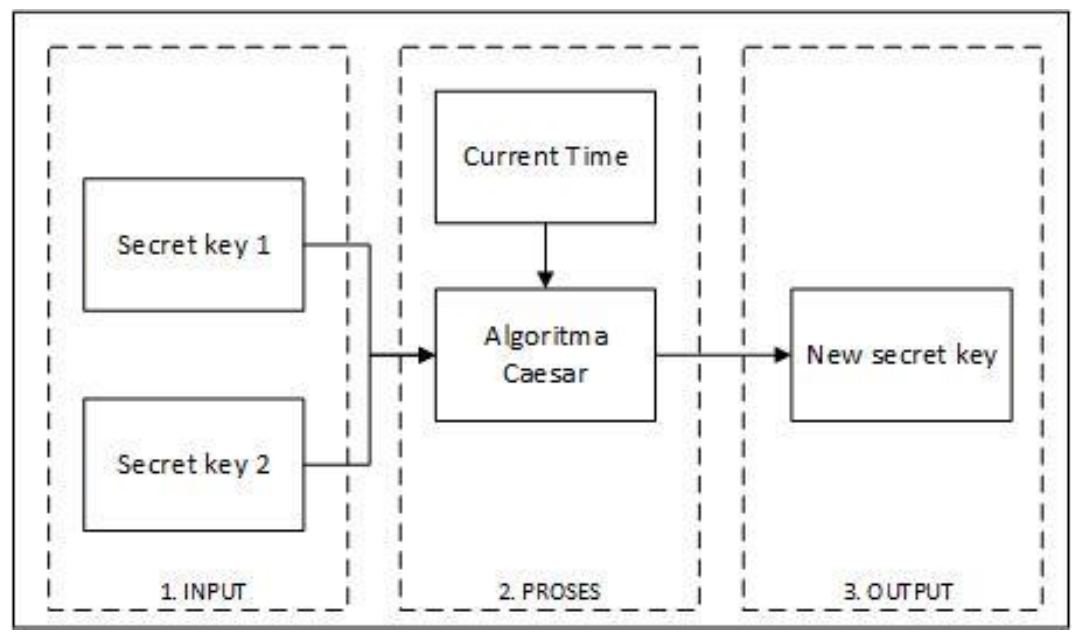

Gambar 3. Penerapan Algoritma Caesar 


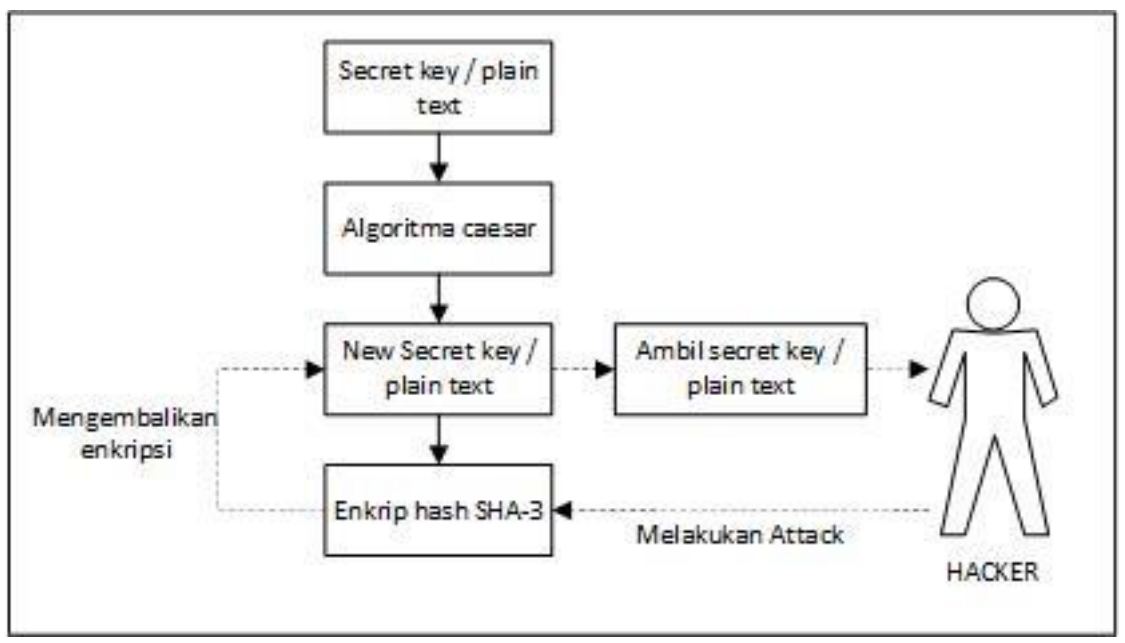

Gambar 4. Skema Hacker

Pada Gambar 4 ditujukan bagaimana jika suatu waktu SHA-3 berhasil diretas dan secret key atau plain text berhasil dicuri oleh hacker, namun secret key atau plain text yang dicuri merupakan hasil enkripsi berdasarkan algoritma caesar yang sudah diproses sebelum melakukan tahap enkripsi algoritma $S H A-3$. Meskipun untuk saat ini $S H A-3$ belum berhasil diretas namun penerapan dengan cara ini menjadi jalan alternatif untuk meningkatkan keamanan kerahasiaan pada password, secret key atau plain text. Gambar 5 menunjukkan blok diagram dari sistem yang akan dijelaskan sebagai berikut :

1. User mengirim pesan "/start" ke sistem melalui telegram.

2. Sistem menerima pesan dari user agar dapat memulai program untuk mendeteksi objek sampah sebagai nilai input.

3. User membuang sampah pada media tempat sampah.

4. Sistem mendeteksi objek sampah lalu men-generate OTP.

5. OTPyang telah digenerate akan dikirim oleh sistem ke user melalui telegram.

6. User akan menerima OTP dari sistem melalui telegram.

7. Sistem menyediakan wifi untuk user.

8. User melakukan tahap koneksi ke wifi dari media tempat sampah.

9. User memasukan password wifi dengan OTP yang telah diterima sebelumnya.

10. OTP bisa diakses selama 3 menit.

11. User dapat melakukan aktivitas melalui internet yang terkoneksi ke wifi selama 3 menit. 


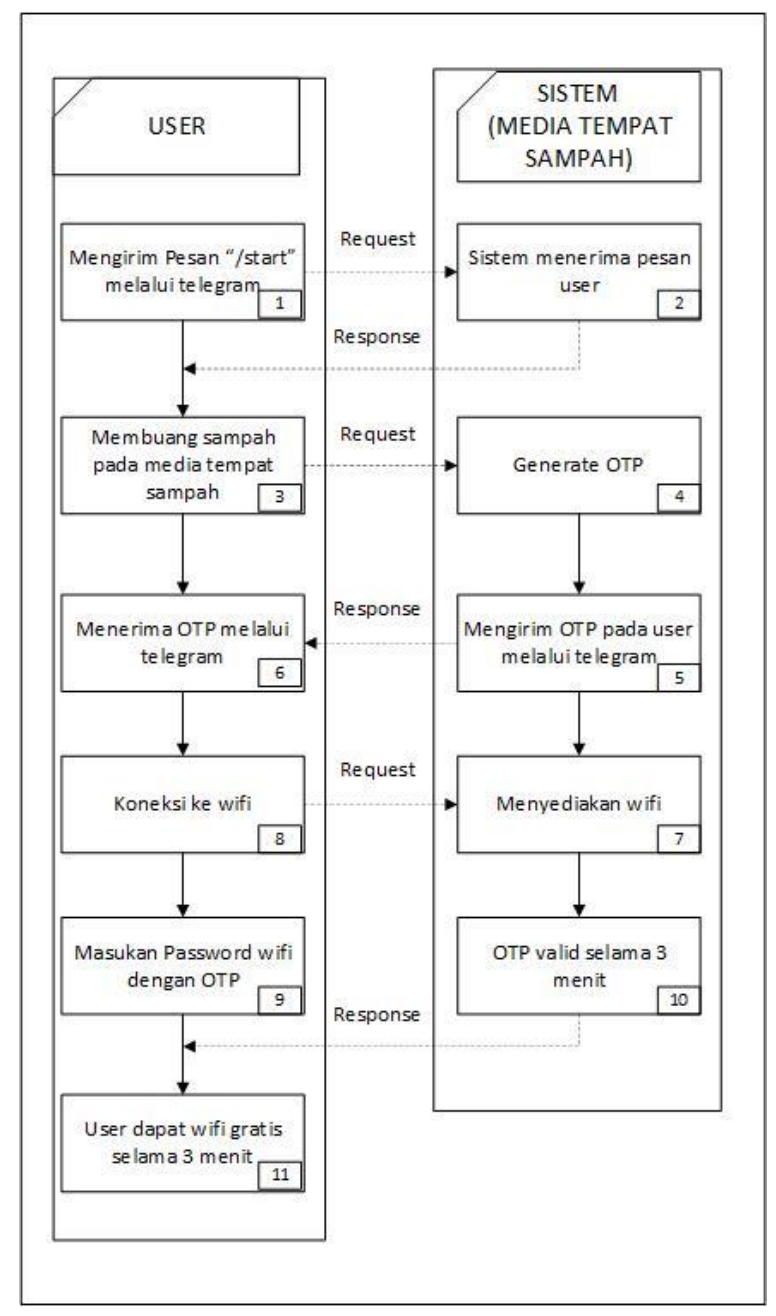

Gambar 5. Blok Diagram Sistem Media Tempah Sampah Wifi

Seperti pada Gambar 6 terdapat beberapa tahapan dalam melakukan pengolahan pada penelitian ini. Berikut merupakan penjelasan-penjelasan dari flowchart pada Gambar 6 tersebut :

1. Registrasi ID : pada tahapan ini dilakukannya registrasi agar sistem dapat mengirim password yang valid kepada client sehingga orang yang membuang sampah dan mendapatkan wifi adalah orang-orang yang sudah terdaftar password akan dikirim via telegram dan untuk registrasi dilakukan secara private, data yang isi berupa informasi pribadi dan token telegram.

2. Sensor : tahapan ini bertujuan untuk mendeteksi objek atau sampah ketika masuk sehingga dapat memberikan kondisi agar sistem dapat memproses atau menjalankan program namun jika sensor terus menerus mendeteksi objek maka sistem akan memberitahu pihak operator bahwa tempat sampah telah penuh dan menghentikan sistem.

3. Program TOTP : adalah tahapan untuk generate TOTP untuk pengelolaan pada password wifi, sehingga password berubah secara dinamis berdasarkan TOTP SHA-3.

4. Pemberian Password: Bertujuan untuk pemberian password yang sudah di-generate oleh program akan dikirim via telegram kepada client yang sudah terdaftar pada telegram.

5. Laporan Ke Admin : setiap laporan atau log dari sistem akan dikirim ke Admin yang nantinya Admin akan menerima laporan atau log tersebut via e-mail. 


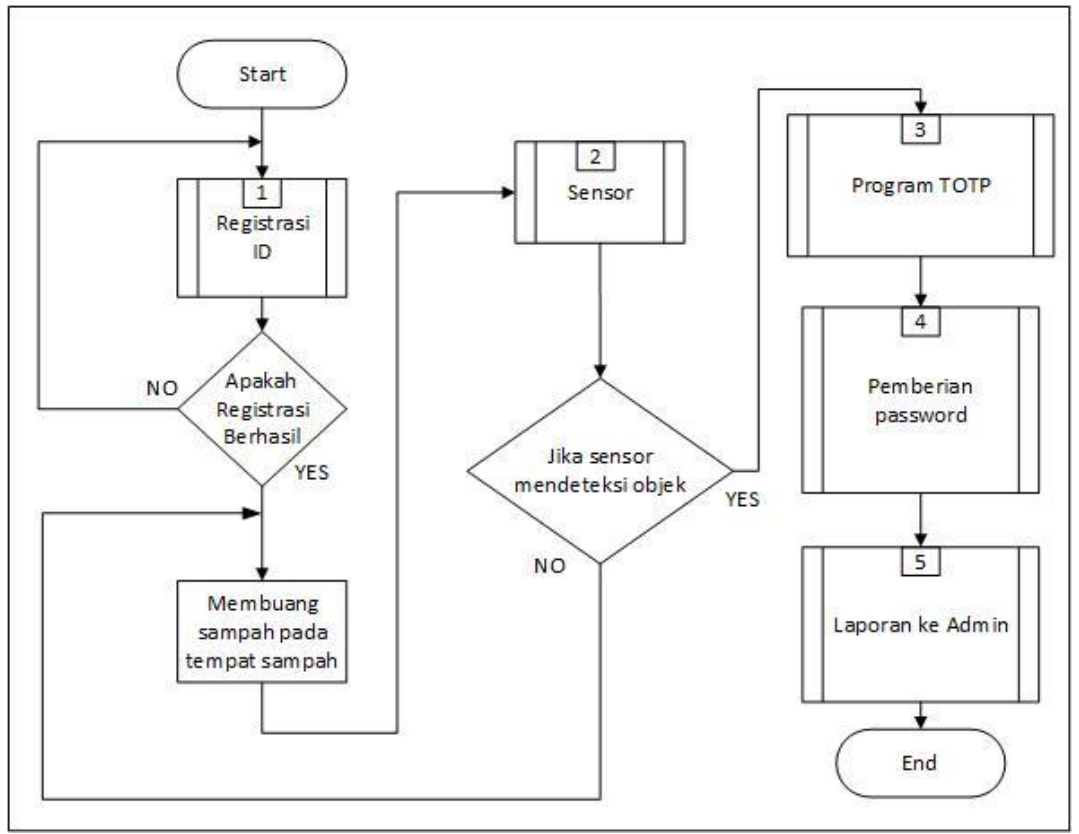

Gambar 6. Flowchart Sistem Pengelolaan Password pada Media Tempat Sampah Wifi

Pada use case yang ditujukan pada Gambar 7 terdapat tiga actor yaitu user, admin dan operator, serta beberapa fungsionalitas pada sistem. Berikut adalah penjelasan dari masingmasing fungsionalitas :

1. Fungsionalitas registrasi $i d$, pada fungsionalitas ini user pertama kali melakukan tahap registrasi kepada pihak admin sehingga admin akan mendaftarkan user dengan memasukan token telegram milik user pada sistem, sehingga user memiliki akses untuk mendapatkan akses wifi dan password wifi.

2. Fungsionalitas deteksi sampah, pada fungsionalitas ini merupakan kegiatan user memasukan objek sampah pada media tempat sampah.

3. Fungsionalitas OTP, pada fungsionalitas ini merupakan generate OTP berdasarkan TOTP SHA-3 pada password wifiyang akan dikirim ke user untuk mengakses wifiselama 3 menit dan dikirim ke pihak admin sebagai laporan log atau aktivitas dari media tempat sampah.

4. Fungsionalitas pemberitahuan jika tempat sampah penuh, pada fungsionalitas ini merupakan pemberitahuan kepada pihak operator jika tempat sampah harus segera dikelola, lalu sistem akan berhenti beroperasi.

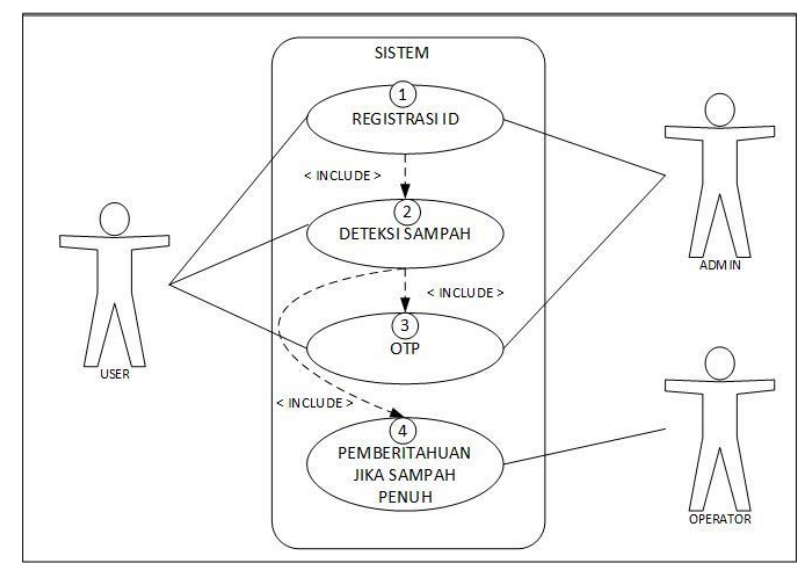

Gambar 7. Use Case Diagram Fungsional Sistem Keseluruhan 


\section{HASIL DAN PEMBAHASAN}

Pada bagian hasil dan pembahasan ini dibahas mengenai bagaimana TOTP SHA-3 dapat diimplementasikan untuk pengelolaan password wifi pada sistem tempat sampah wifi dan dapat men-generate password wifi untuk sekali diakses dalam batas waktu yang ditentukan. Berikut adalah blok diagram umum bagaimana sistem bekerja dan saling berhubungan yang ditujukan pada Gambar 8.

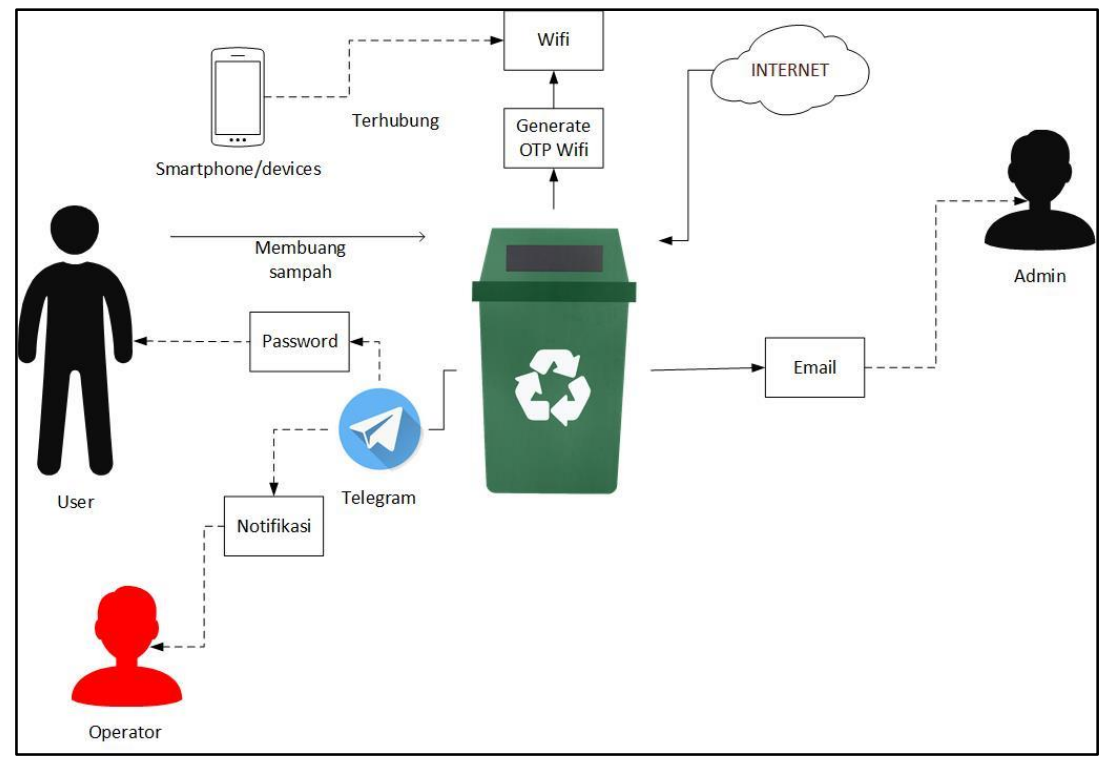

Gambar 8. Implementasi Sistem Pengelolaan Password pada Sistem Tempat Sampah Wifi

Pada Gambar 9 ditunjukan hasil dari perancangan seluruh hardware dari prototype tempat sampah dan perancangan alat.

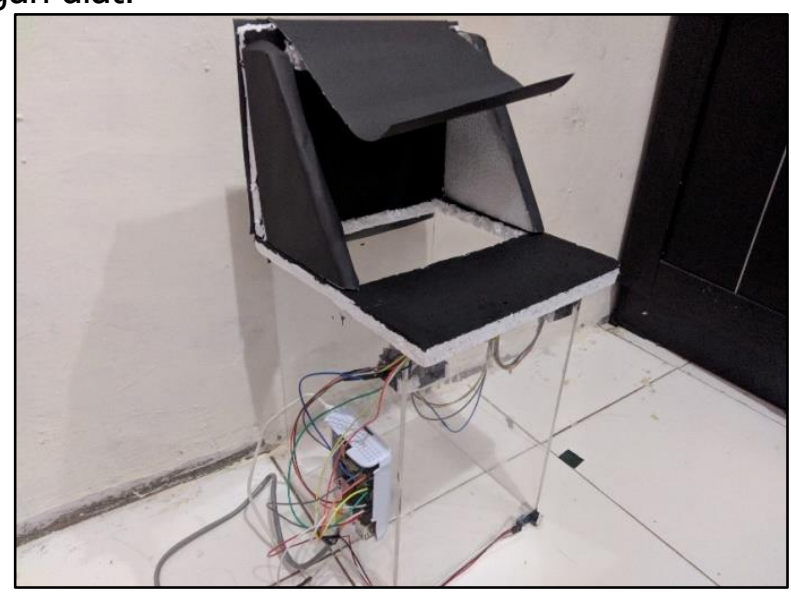

Gambar 9. Implementasi Hardware Prototype Sistem

Subsistem telegram memanfaatkan Internet of thing sebagai suatu inovasi dimana mesin dapat berkomunikasi dengan manusia secara mandiri dan tidak ada campur tangan dari manusia, selama raspberry pi terhubung ke internet maka opsi fitur komunikasi yang akan digunakan cukup banyak salah satunya aplikasi chatting telegram sehingga pemanfaatan internet yang mana adalah inti dari IoT dapat diimplementasikan pada sistem dengan menggunakan bot telegram pada python raspberry, bot telegram akan memiliki dua akun yang dapat berkomunikasi dengan raspberry pi yaitu User dan Operator, User berperan 
sebagai penerima password wifi yang nantinya akan dikirim melalui telegram dari sistem sedangkan Operatorberperan me-manage kapasitas sampah jika penuh dan memberi perintah untuk menjalakan sistem jika tempat sampah sudah siap beroperasi.

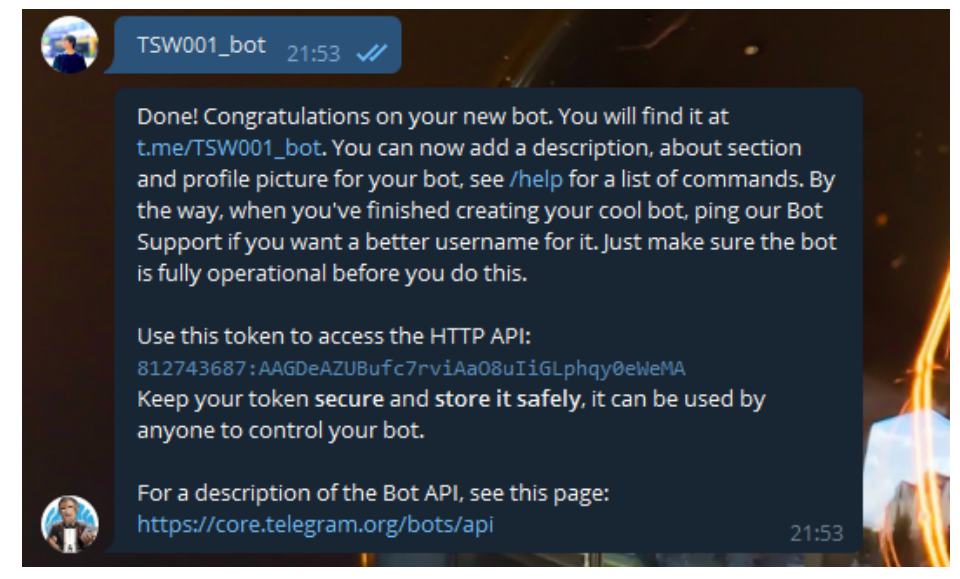

\section{Gambar 10. Bot Telegram}

Berikut ini merupakan pengujian kemiripan hasil keluaran TOTP dengan skenario sebagai berikut :

Skenario Awal : : Hasil keluaran di-generate dalam dua waktu yang berbeda.

Tujuan

: Membandingkan kemiripan dari kedua hasil generate .

Waktu Pengujian : 21-09-2020 pada pukul 15:30

Pengujian dilakukan dengan mencetak 50 password dalam dua waktu yang berbeda, hasil keluaran dibandingkan dengan menggunakan tool yang bernama text compare. Perbandingannya ditunjukan pada Gambar 11 sebagai berikut.

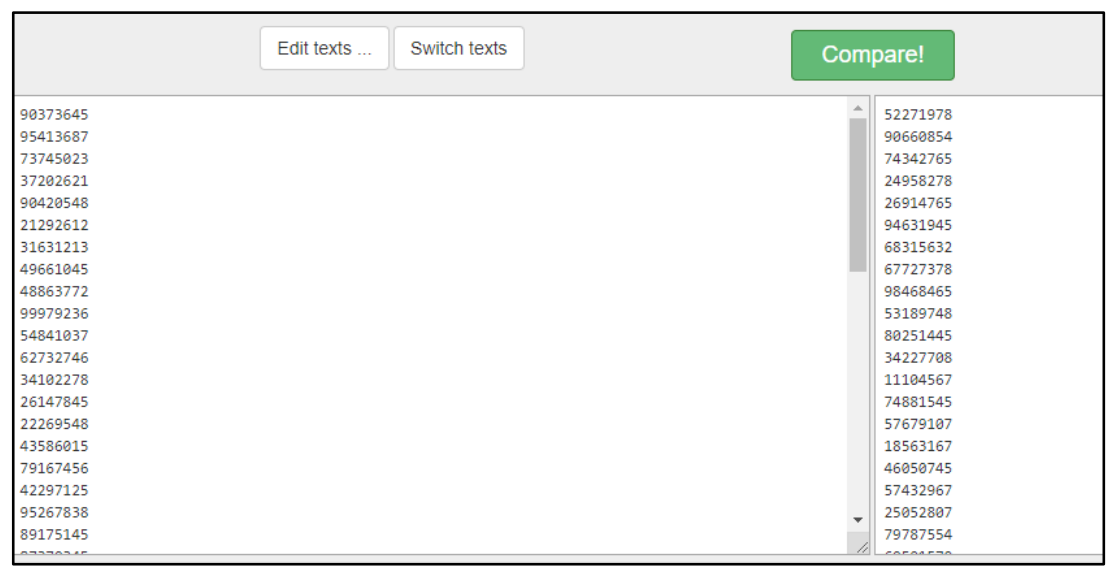

Gambar 11. Komparasi OTP

Saat dibandingkan terdapat satu password yang memiliki tingkat kemiripan yang tinggi, seperti yang ditujukan pada Gambar 12 sebagai berikut.

\section{$35 \quad 94634378 \quad 6 \quad 94631945$}

Gambar 12. Kemiripan TOTP

Dari 50 password terdapat kemiripan password dengan jumlah digit 5 berupa deretan angka "94563" pada kedua hasil keluaran password, sehingga presentase dengan tingkat kemiripan 
sebesar $\frac{01}{50}=0,02 \%$. Pada hasil pengujian didapatkan perolehan jumlah objek terdeteksi dengan hasil sebesar $100 \%$ pada jeda 6 detik untuk pengujian alpha satu sensor.

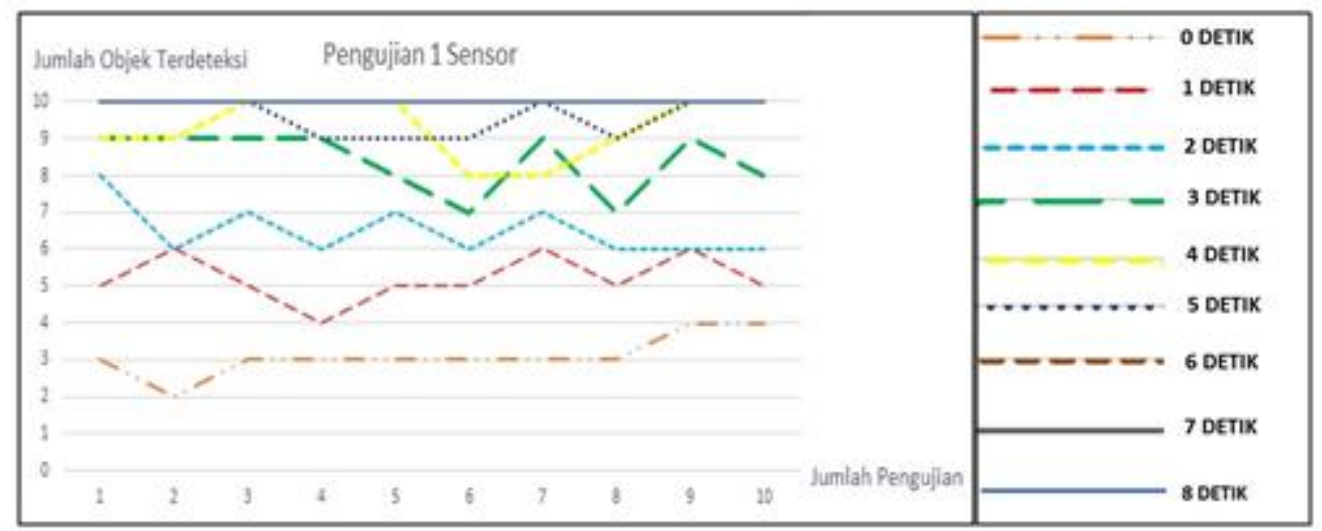

Gambar 13. Grafik Pengujian Alpha Satu Sensor

Berikut ini merupakan pengujian Beta implementasi Hardware yang terdapat pada Gambar 14. Pada saat kertas atau objek sampah dimasukan ke tempat sampah dengan posisi horizontal dan diagonal akan terdeteksi oleh dua sensor ultrasonik yang sebelumnya sudah dijalankan oleh operator melalui telegram, sensor ultrasonik akan mendeteksi objek jika terjadi perubahan deteksi jarak, ketika adanya perubahan maka perubahan tersebut akan dijadikan suatu nilai analog dan men-trigger untuk menjalankan sistem.

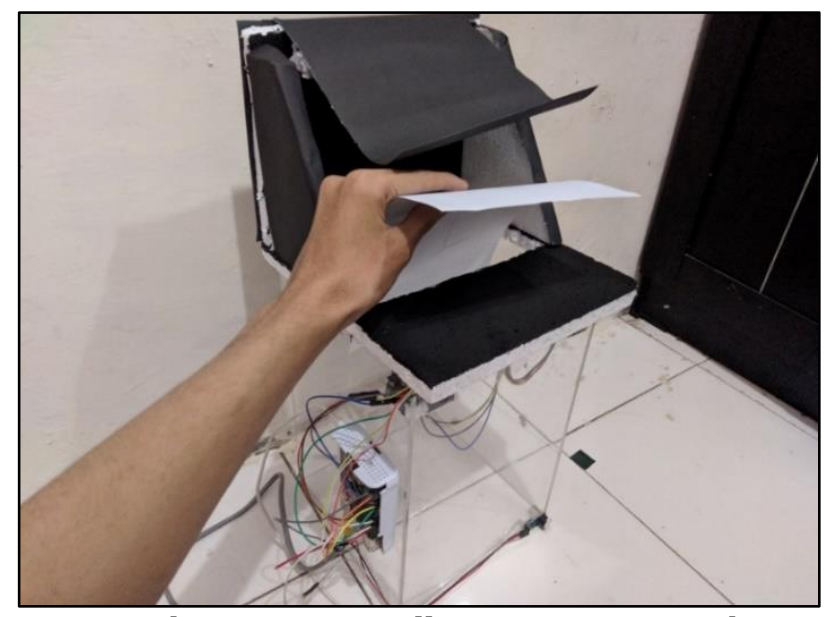

Gambar 14. Pengujian Buang Sampah

Gambar 15 menunjukkan hasil uji konektivitas dari smartphone, hasil yang didapat adalah smartphone dapat terkoneksi dengan wifi, secara otomatis smartphone mendapatkan ip dhcp dan mendapatkan akses internet. 


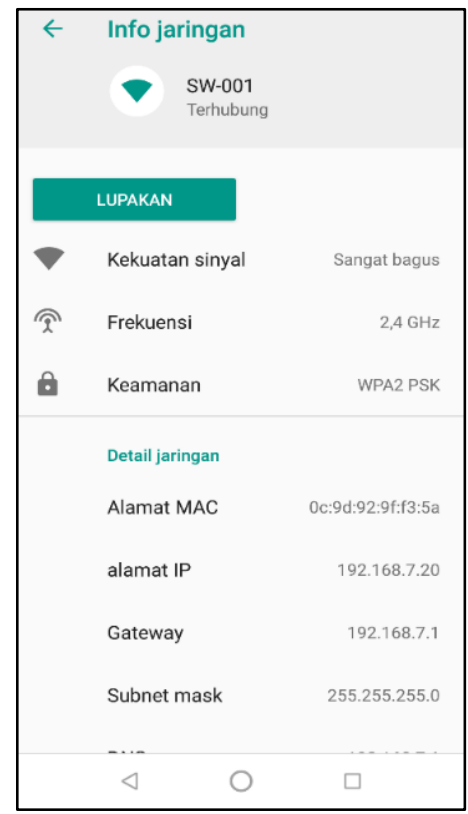

Gambar 15. Pengujian Konektivitas

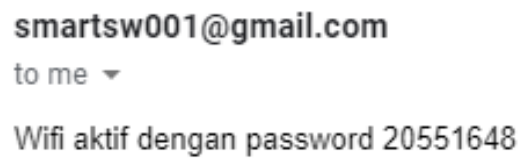

Gambar 16. Pengujian Email Diterima Admin

Gambar 16 menunjukkan bahwa admin secara otomatis mendapatkan email dari tempat sampah mengenai aktivitas saat WiFiaktif beserta password WiFiyang valid.

Gambar 17 menunjukan grafik dari pengujian beta, implementasi algoritma TOTP SHA-3 pada sistem sampah wifimenunjukan berapa perolehan waktu dalam detik yang didapat saat sistem mendeteksi objek sampah dan mengirim password wifike telegram, perolehan rata-rata waktu yang didapat adalah 0,45 detik.

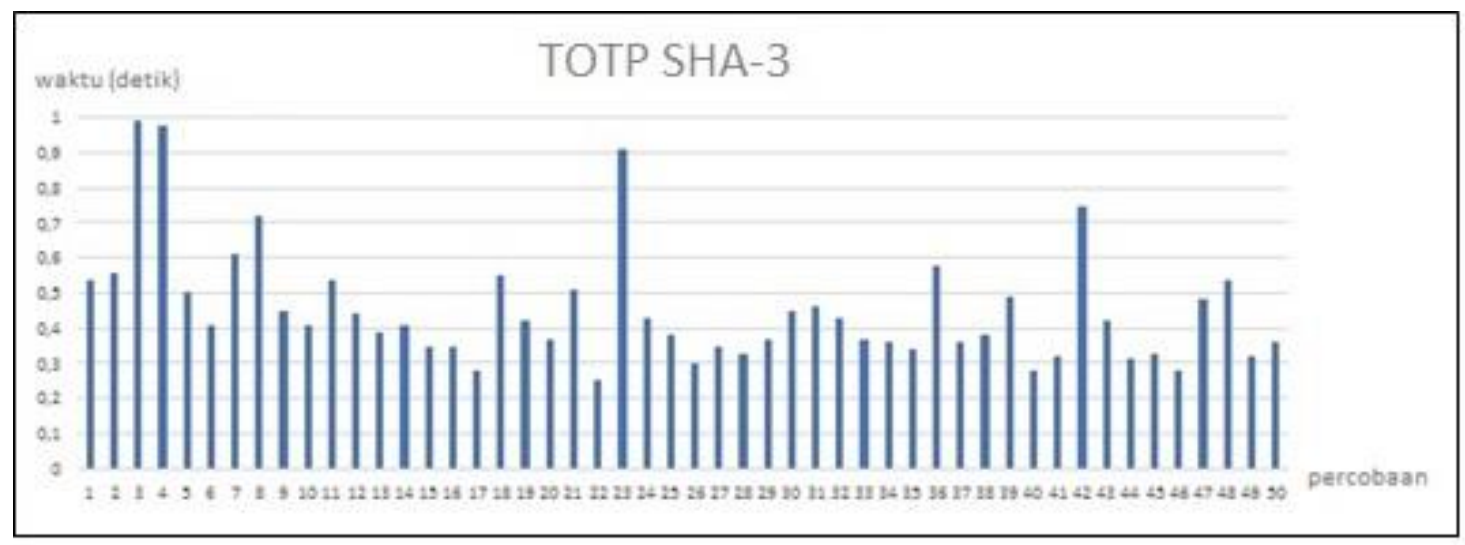

Gambar 17. Pengujian Beta Algoritma TOTP SHA-3

Pada Gambar 18 didapatkan perolehan jumlah objek terdeteksi dengan hasil sebesar $100 \%$ pada jeda 5 detik untuk pengujian beta dua sensor. 


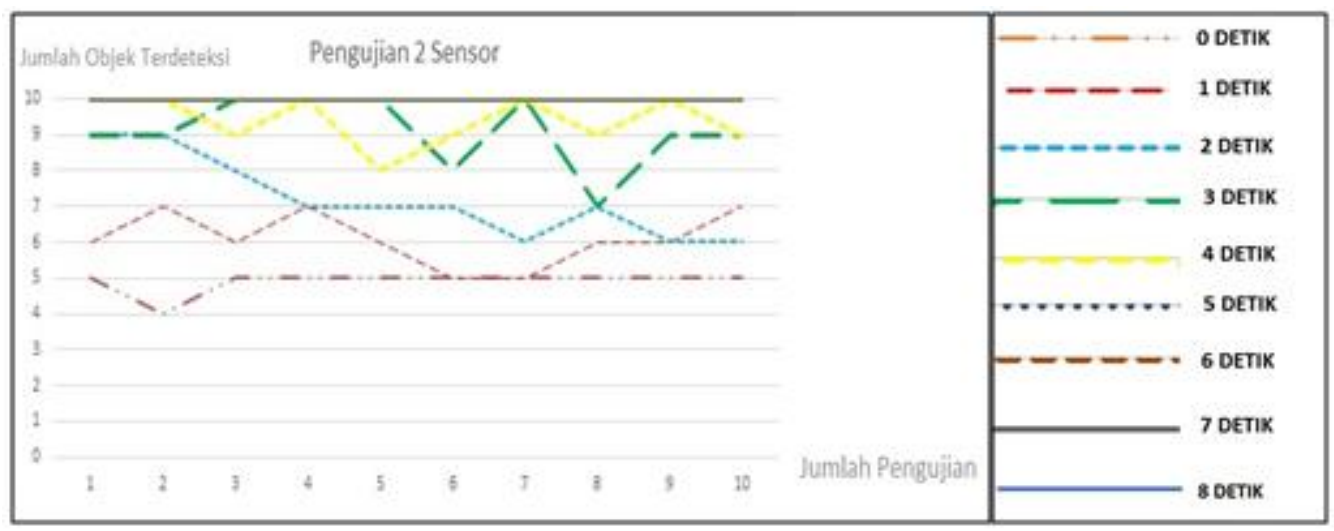

Gambar 18. Grafik Pengujian Beta Dua Sensor

\section{KESIMPULAN}

Kesimpulan yang didapat pada penelitian algoritma TOTP SHA-3 untuk pengelolaan pasSword wifi pada media tempat sampah ini adalah penerapan enkripsi $S H A-3$ dapat menjaga kerahasiaan password yang telah diuji dengan brute attack, penerapan algoritma caesar pada TOTP membuat variasi password yang banyak dan meningkatkan kerahasiaan password sebagai lapis keamanan kedua. Pada pengujian jeda waktu dengan 1 sensor diperoleh presentase $100 \%$ pada jeda waktu 6 detik dan dengan 2 sensor diperoleh presentase $100 \%$ pada jeda waktu 5 detik sehingga sensor dapat mendeteksi objek dengan baik jika ada waktu jeda untuk merespon selama 5 detik. Dari hasil pengujian keluaran password tidak terdapat kemunculan password yang berulang namun memiliki tingkat kemiripan password sebesar $0,02 \%$.

Sistem tempat sampah wifi digunakan sebagai implementasi sistem dengan hasil pengujian sistem mampu mengidentifikasikan akun telegram yang teregistrasi dengan menggunakan token, mendeteksi objek dengan sensor ultrasonik, menghasilkan password wifiberbasis TOTP $S H A-3$, mengirim password wifi melalui telegram dan mencatat laporan ke admin melalui $e$ mail.

\section{DAFTAR RUJUKAN}

Andriani, D. (2020). Perlunya Tingkatkan Jaringan Internet di Masa New Normal. Diambil kembali dari https://teknologi.bisnis.com/read/20200805/84/1275606/perlunyatingkatkan-jaringan-internet-di-masa-new-normal

Chandra, H. A., Wijaya, Y. I., \& Budiman, H. (2019). Algoritma One Time Password pada Sistem Informasi Penerimaan Sistem Baru Online SMP H.A Johansyah A Banjarmasin. (hal. 207-211). Technologia.

Fakhrusy, M. (2016). Implementasi HMAC-SHA-3-Based One Time Password pada Skema TwoFactor Authentication. 1-6. 
Huseynov , E., \& Seigneur, J.-M. (2016). WiFiOTP : Pervasive two-faktor Autentication using Wi-Fi SSID Broadcasts. Proceedings of the 2015 ITU Kaleidoscope : Trust in the Information Society, K-2015-Academic Conference.

Janakiraman, S., Sree, K. S., Manasa, V. L., \& Rajagopalan, S. (2018). 2018 International Conference on Computer Communication and Informatics (ICCI), (hal. 1-2).

Kolhatkar, C., Joshi, B., Choudhari, P., \& Bhuva, D. (2018). Smart E-dusbin. International Conference on Smart City and Emerging Technology, ICSCET, (hal. 1-3).

Kurniawan, F., Kusyanti, A., \& Nurwasito, H. (2017). Analisis dan Implementasi Algoritma SHA1 dan SHA-3 pada Sistem Autentikasi Garuda Training Cost. Jurnal Pengembangan Teknologi Informasi dan IImu Komputer, 803-812.

Ramadhany, T. (2016). Authentication, K.M., \& Hmac, C. (n.d).Keyed-has Message Authentication Code (HMAC).

Singh, A., \& Raj, S. (2019). Securing Password using Dynamic Password Policy Generator Algorithm. Journal of King Saud University - Computer and Information Sciences.

Ungkawa, U., Dewi, I. A., \& Putra, K. R. (2013). Implementasi Algoritma Tme-Based One Time Password dalam Otentikasi Token Internet Banking. Teknik Informatika Fakultas Teknologi Industri Institut Teknologi Nasional Bandung, 2-11. 